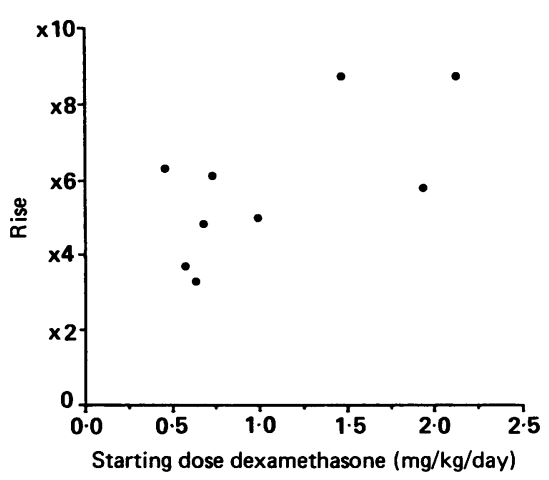

Figure 1 Weight change during first week.

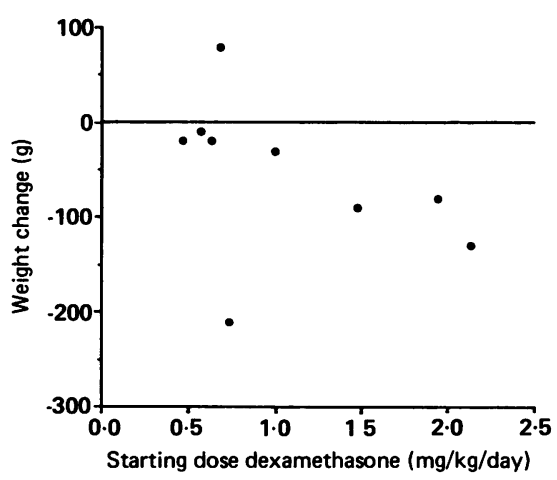

Figure 2 Rise in blood urea concentrations.

the week before treatment (before treatment mean $0.87 \mathrm{mmol} / 1$ and on treatment mean 4.73 $\mathrm{mmol} / \mathrm{l})$. This catabolic state appeared to be a dose related effect (see figs 1 and 2).

The importance of adequate nutrition in premature infants is well accepted and the likelihood of inducing a catabolic state should be borne in mind when considering dexamethasone treatment. Future studies of growth and nutrition in premature infants should take into account the use of dexamethasone, and further studies of the role of dexamethasone in bronchopulmonary dysplasia should include the effectiveness of lower dose treatment.

$$
\begin{array}{r}
\text { P D MACDONALD } \\
\text { P GALEA } \\
\text { L G ALROOMI } \\
\text { Glasgow Royal Matemity Hospital, } \\
\text { Rottenrow, Glasgow } \\
\text { G4 ONA }
\end{array}
$$

1 Mammel MC, Green TP, Johnson DE, et al. Controlled trial of dexamethasone therapy in infants with bronchopulmonary dysplasia. infants with bronch

2 Avery GB, Fletcher AB, Kaplan M, et al. Controlled trial of dexamethasone in respirator trolled trial of dexamethasone in respirator
dependent infants with bronchopulmonary dysplasia. Pediatrics 1985;75:106-11.

\section{Which routine test for kidney function?}

SIR,-In a recent article Parkin, Smith, and Brocklebank studied some simple tests for assessing glomerular filtration rate in children with known renal disease. ${ }^{1}$ One of the tests studied performed better than the others. It was a height:creatinine index, where a value below $2 \cdot 1$ indicated a low glomerular filtration rate with a sensitivity of $91 \%$.

The calculations for the predictive values of

\begin{tabular}{|c|c|c|c|c|}
\hline & \multirow[t]{2}{*}{ Test result } & \multicolumn{2}{|c|}{ Plasma clearance of ${ }^{5 I} \mathrm{Cr}$ edetic acid } & \multirow[t]{2}{*}{ Total } \\
\hline & & $<80 \mathrm{ml} / \mathrm{min}$ & $>80 \mathrm{ml} / \mathrm{min}$ & \\
\hline \multirow[t]{2}{*}{ Height:creatinine $<2 \cdot 1$} & \pm & $\begin{array}{r}20 \\
2\end{array}$ & $\begin{array}{l}100 \\
378\end{array}$ & $\begin{array}{l}120 \\
380\end{array}$ \\
\hline & & 22 & 478 & 500 \\
\hline \multicolumn{5}{|l|}{ Table 2} \\
\hline & \multirow[t]{2}{*}{ Test result } & \multicolumn{2}{|c|}{ Plasma clearance of ${ }^{51} \mathrm{Cr}$ edetic acid } & Total \\
\hline & & $<80 \mathrm{ml} / \mathrm{min}$ & $>80 \mathrm{ml} / \mathrm{min}$ & \\
\hline \multirow[t]{2}{*}{ Height:creatinine $<1.5$} & + & $\begin{array}{r}15 \\
7\end{array}$ & $\begin{array}{r}10 \\
468\end{array}$ & $\begin{array}{r}25 \\
475\end{array}$ \\
\hline & & 22 & 478 & 500 \\
\hline
\end{tabular}
the different tests, however, have also been calculated from the 80 samples in their study.

Table 1

Twenty two of these were from patients with a low glomerular filtration rate. The prevalence of low glomerular filtration rate in this group is $28 \%$. The prevalence of the disease, for which one is looking in the tested population, influences the predictive values for the test quite a lot. The only thing the reader of the article knows about these children is that they all have a renal disease, and that the physician caring for them has decided to measure their glomerular filtration rate by ${ }^{51} \mathrm{Cr}$ edetic acid clearance. A prevalence of low glomerular filtration rate of $28 \%$ in this group means that the process of selecting these 72 children, who were tested, from all the others with known renal disease has been quite efficient. The authors now propose that this unknown procedure is to be replaced by using height: creatinine $<2 \cdot 1$ as the selecting instrument for suspicion of low glomerular filtration rate. Let us see what happens. The prevalence of reduced glomerular filtration rate is low in the population. Let us presume that the general practitioners with an interest in paediatrics, who are the non-nephrologists the authors recommend the test for, will have to think about the renal function in at least 500 cases of renal disease before they will find 22 cases with low glomerular filtration rate. Using the sensitivity and specificity given in the article we can calculate the following table (see above: table 1).

From this table we can get the predictive value of a normal test to be $99 \%$, but the predictive value of an abnormal test is only $17 \%$.

The authors don't recommend the height: creatinine index $<1.5$ because its sensitivity is too low. What will happen if we apply it to the 500 children we are talking about with a renal disease and unknown renal function? (see above: table 2).

The predictive value of a normal test is still very good, $98 \%$, and the predictive value of a pathological test is much better, $60 \%$. But this test leaves one third of the group we are looking for undetected. So even if we only have to make 25 clearance tests to find 15 of the 22 with a low glomerular filtration rate compared with 120 clearance investigations to find 20 of them, the five we lose by this method can be quite important.

But both these calculations are based on the assumption that the risk for a low glomerular filtration rate is evenly distributed in the 500 individuals, and that the height:creatinine index will work in the same way in all cases. I don't think that is true. These children all had a known renal disease, and the risk of having a low glomerular filtration rate must be different between diagnosis. If, by using this information, one can reduce the group of 500 children to a more manageable lot of say 100 , and then by applying the height:creatinine index as the authors suggest and with the value $<2 \cdot 1$, the whole procedure will work quite well. I think that is what the authors have done, but they must not keep the hidden part of the screening they have performed hidden from the reader.

S BLOMSTRAND Department of Paediatrics, Lasarettet, Box 850, $S-50115$ Boras, Sweden

1 Parkin A, Smith HC, Brocklebank JT. Which routine test for kidney function? Arch Dis Child 1989;64:1261-3.

Drs Parkin and Brocklebank comment:

The purpose of the study was to help paediatricians to identify children with reduced glomerular filtration rate and then to decide when to refer those children to a specialist paediatric nephrology centre. We accept the analysis of Dr Blomstrand but the context of our investigation was not screening for reduced glomerular filtration rate in the general population. Given that the children have established renal disease, the decision as to which diagnostic test to use must be made. To this end we have identified normal ranges of $\beta_{2}$ microglobulin and plasma creatinine concentrations in children who have measured normal glomerular filtration rate and given some guidance about which is the most appropriate test to use.

We would agree that this is not an unscreened population and that the results in the general population might be different.

Neonatal purpura fulminans and transient protein $\mathbf{C}$ deficiency

SIR,-We present a unique case of an otherwise well neonate presenting with purpura fulminans due to transient protein $C$ deficiency.

A $4310 \mathrm{~g}$ girl was born to unrelated parents after an uncomplicated pregnancy and delivery. There was no relevant family history. Vitamin $K_{1}$ was injected at birth and a routine examination showed a healthy infant. From 7 hours of age there was rapid development of areas of 'bruising' affecting the trunk and limbs typical of purpura fulminans. Her vital signs were normal. At 18 hours of age she had a right sided clonic convulsion. Oliguria was present with the serum creatinine concentration rising to $114 \mu \mathrm{mol} / \mathrm{l}$. Ultrasound of the heart and brain and a renal isotope scan were normal. The full blood count, prothrombin time, and activated partial thromboplastin time were normal. A septic screen was clear. The clinical picture was consistent with 